Research Paper

\title{
Cross-talk between two antioxidants, thioredoxin reductase and heme oxygenase-1, and therapeutic implications for multiple myeloma
}

\author{
Prahlad V. Raninga ${ }^{\mathrm{a}, \mathrm{b}}$, Giovanna Di Trapani ${ }^{\mathrm{a}}$, Slavica Vuckovic ${ }^{\mathrm{c}, \mathrm{d}}$, Kathryn F. Tonissen ${ }^{\mathrm{a}, \mathrm{b}, *}$ \\ a School of Natural Sciences, Griffith University, QLD 4111, Australia \\ b Eskitis Institute for Drug Discovery, Griffith University, QLD 4111, Australia \\ ' QIMR Berghofer Medical Research Institute, Brisbane, QLD 4006, Australia \\ ${ }^{\mathrm{d}}$ The University of Queensland, QLD 4072, Australia
}

\section{A R T I C L E I N F O}

\section{Article history:}

Received 30 November 2015

Received in revised form

5 January 2016

Accepted 8 January 2016

Available online 11 January 2016

Keywords:

Thioredoxin reductase

Heme oxygenase- 1

Multiple myeloma

Chemoresistance

Apoptosis

\begin{abstract}
A B S T R A C T
Multiple myeloma (MM) is characterized by an accumulation of abnormal clonal plasma cells in the bone marrow. Despite recent advancements in anti-myeloma therapies, MM remains an incurable disease. Antioxidant molecules are upregulated in many cancers, correlating with tumor proliferation, survival, and chemoresistance and therefore, have been suggested as potential therapeutic targets. This study investigated the cross-talk between two antioxidant molecules, thioredoxin reductase (TrxR) and heme oxygenase-1 (HO-1), and their therapeutic implications in MM. We found that although auranofin, a TrxR inhibitor, significantly inhibited TrxR activity by more than $50 \%$ at lower concentrations, myeloma cell proliferation was only inhibited at higher concentrations of auranofin. Inhibition of TrxR using lower auranofin concentrations induced HO-1 protein expression in myeloma cells. Using a sub-lethal concentration of auranofin to inhibit TrxR activity in conjunction with HO-1 inhibition significantly decreased myeloma cell growth and induced apoptosis. TrxR was shown to regulate HO-1 via the Nrf2 signaling pathway in a ROS-dependent manner. Increased HO-1 mRNA levels were observed in bortezomib-resistant myeloma cells compared to parent cells and HO-1 inhibition restored the sensitivity to bortezomib in bortezomib-resistant myeloma cells. These findings indicate that concurrent inhibition of HO-1 with either a TrxR inhibitor or with bortezomib would improve therapeutic outcomes in MM patients. Hence, our findings further support the need to target multiple antioxidant systems alone or in combination with other therapeutics to improve therapeutic outcomes in MM patients.
\end{abstract}

(c) 2016 The Authors. Published by Elsevier B.V. This is an open access article under the CC BY-NC-ND license (http://creativecommons.org/licenses/by-nc-nd/4.0/).

\section{Introduction}

Multiple myeloma (MM) is a malignant neoplasm of plasma cells characterized by an aberrant accumulation of plasma cells in the bone marrow (BM). In recent years, new therapeutics including proteasome inhibitors, bortezomib [1] and carfilzomib [2], and immunomodulatory drugs thalidomide [3] and lenalidomide [4] significantly improve MM patient outcome. Despite such developments in MM treatment, relapse is inevitable, and MM remains

\footnotetext{
Abbreviations: AF, Auranofin; AML, Acute myeloid leukemia; ANOVA, Analysis of variance; AP-1, Activator protein-1; ARE, Antioxidant response element; BM, Bone marrow; Btz, Bortezomib; CLL, Chronic lymphocytic leukemia; CML, Chronic myeloid leukemia; CuPP IX, Copper Protoporphyrin IX; HIF-1 $\beta$, Hypoxia inducible factor- 1 beta; HO-1, Heme oxygenase-1; MM, Multiple myeloma; NF-к $\beta$, Nuclear factor kappa beta; Nrf2, Nuclear factor-E2-related factor 2; PBMCs, Peripheral blood mononuclear cells; ROS, Reactive oxygen species; Trx, Thioredoxin; TrxR, Thioredoxin reductase; ZnPP IX, Zinc Protoporphyrin IX

* Corresponding author at: School of Natural Sciences, Nathan Campus, Griffith University, Brisbane, QLD 4111, Australia.

E-mail address: K.Tonissen@griffith.edu.au (K.F. Tonissen).
}

an incurable disease with the median survival rate of 3-5 years. Thus, better understanding of the myeloma biology and the mechanisms underlying chemoresistance can help to develop new therapeutic modalities with the potential to cure MM.

Heme oxygenase-1 (HO-1) is a cytoprotective enzyme catalyzing the conversion of intracellular heme into biliverdin, free iron, and carbon monoxide [5]. Biliverdin reductase further reduces biliverdin into a potent antioxidant bilirubin [6,7], which possesses anti-inflammatory, anti-oxidative, and anti-apoptosis properties $[8,9]$. Elevated HO-1 expression and activity have been observed in various cancer types including renal cell carcinoma [10], prostate cancer [11], lymphosarcoma [12], melanoma [13], chronic myeloid leukemia (CML) [14], and chronic lymphocytic leukemia (CLL) [15]. Moreover, HO-1 expression has been shown to increase in response to the treatment with chemotherapeutic agents in acute myeloid leukemia (AML) [16], CML [17], pancreatic cancer [11], and MM [18]. Inhibition of upregulated HO-1 has been demonstrated to reverse the chemoresistance and resensitizes cancer cells to the chemotherapeutic agents in many human cancer types [11,16,17]. Thus, HO-1 serves as a potential therapeutic target in cancer either 
alone or in conjunction with conventional chemotherapeutic agents. Although bortezomib treatment increased HO-1 mRNA levels in MM [18], the functional role of HO-1 in myeloma cell survival, growth, and bortezomib resistance has not been established. The expression of HO-1 is regulated by many transcription factors including nuclear factor-к $\beta$ (NF-к $\beta$ ) $[19,20]$, NF-E2-related factor 2 (Nrf2) [21], activator protein-1 (AP-1) [22], and Bach-1 [23]. However, how HO-1 is regulated in myeloma cells is unclear.

The thioredoxin (Trx) system is one of the major cellular antioxidant systems and is comprised of thioredoxin (Trx), thioredoxin reductase (TrxR), and NADPH [24]. Both Trx1 and TrxR1 have been shown to be upregulated in many human cancer types including MM, and correlated with cancer cell survival, growth, resistance to apoptosis, and drug resistance [25,26]. Although the Trx system is a major antioxidant system involved in multiple redox-regulated signaling pathways in cancer [27,28], it also interacts with other antioxidant systems. Upon the loss of one antioxidant system, the cell may activate another antioxidant or stress molecule to compensate for the loss and protect themselves against increased oxidative stress and chemotherapeutic drugs [29-31]. Several lines of evidence indicate the involvement of the Trx/TrxR system in the regulation of HO-1 expression [31-33]. Inhibition of TrxR using pharmacological inhibitors, such as aurothioglucose, induces HO-1 expression and activity. Moreover, TrxR inhibition using auranofin has also increased HO-1 expression in an oxidative stress-dependent manner in CLL cells [34]. However, the role of TrxR in regulating HO- 1 and the therapeutic implications of targeting both TrxR and HO-1 together in MM remains unclear.

The present study was designed to study the cross-talk between the two antioxidants, TrxR and HO-1 in MM, and the therapeutic implication of targeting both in conjunction in myeloma cells. Our results show that TrxR inhibition induces HO-1 expression through the Nrf2 signaling pathway. We show that HO1 inhibition using a pharmacological inhibitor, Zinc Protoporphyrin IX (ZnPP IX), sensitizes myeloma cells to undergo apoptosis in response to TrxR inhibition at the lower concentrations of auranofin. Thus, HO- 1 acts as a secondary anti-apoptotic mechanism and is upregulated to compensate for the loss of TrxR functions. Our data also show that HO-1 expression is increased in bortezomib-resistant myeloma cells and its inhibition restores the sensitivity to bortezomib. These findings suggest concurrent inhibition of HO-1 with either a TrxR inhibitor or with bortezomib would improve therapeutic outcomes in MM patients.

\section{Materials and methods}

\subsection{Cells and reagents}

The standard human myeloma cell lines (RPMI8226, U266, and OPM2) were obtained from Dr. Slavica Vuckovic (QIMR Berghofer Medical Research Institute). RPMI8226 cells were originally derived from the peripheral blood of a 61-year-old male with multiple myeloma (IgG lambda-type) [35]. U266 cells were originally derived from the peripheral blood of a 53-year-old male with IgEsecreting myeloma (refractory) [36]. OPM2 cells were originally derived from the peripheral blood of 56-year-old woman with multiple myeloma in leukemic phase (relapse) [37]. Human peripheral blood mononuclear cells (PBMCs) were isolated from the whole blood of healthy volunteers and were collected under the ethical approval BPS/08/14/HREC. Cells were cultured in RPMI1640 medium (Gibco) containing 10\% (v/v) fetal bovine serum (FBS) (Bovagen), $200 \mathrm{mM} \mathrm{L-glutamine,} \mathrm{and} 100 \mathrm{U} / \mathrm{ml}$ penicillin and $100 \mu \mathrm{g} / \mathrm{ml}$ streptomycin (Invitrogen). The monoclonal anti-HO-1 antibody was purchased from R \& D Systems. The monoclonal anti-Nrf2 antibody, anti-Lamin B1, and anti- $\beta$-tubulin antibodies were purchased from Abcam. The monoclonal anti-HIF-1 $\beta$ antibody was purchased from BD Biosciences. The TrxR1 inhibitor auranofin was purchased from Sigma. An HO-1 inhibitor ZnPP IX and its control compound CuPP IX were purchased from Enzo Life Sciences. The dominant negative-Nrf2 plasmid was kindly provided by Dr. Xilin Chen (Atherogenics, USA) [38].

\subsection{TrxR activity assay}

RPMI8226, U266, and OPM2 cells were treated with auranofin $(0-2 \mu \mathrm{M})$ for $24 \mathrm{~h}$ in 6 -wells plate. The TrxR activity assays were performed as described previously [39]. Briefly, treated and untreated cells were lysed using $0.5 \%(\mathrm{v} / \mathrm{v})$ Nonidet P-40 cell lysis buffer $(150 \mathrm{mM} \mathrm{NaCl}, 50 \mathrm{mM}$ Tris-Cl, pH 8; 0.5\% (v/v) Nonidet P-50, 0.5 mM EDTA, 2 mM PMSF, $1 \mu \mathrm{l} / \mathrm{ml}$ protease inhibitor cocktail VI, $1 \times$ PBS). To omit non-TrxR1-specific DTNB reduction, cell lysates were treated with or without $8 \mu \mathrm{M}$ auranofin for $30 \mathrm{~min}$ at room temperature. The TrxR activity was measured using a buffer containing $0.5 \mathrm{M}$ potassium phosphate, $200 \mathrm{mM}$ EDTA, $20 \mathrm{mM}$ $\mathrm{NADPH}$, and $125 \mathrm{mM}$ DTNB. TNB production was measured by following an increase in absorbance at $412 \mathrm{~nm}$ for $10 \mathrm{~min}$. The reaction rates obtained in the presence of auranofin were subtracted from the reaction rates obtained in the absence of auranofin to give the final corrected TrxR rates. Units of TrxR activity ( $\mu$ moles of TNB produced/minute) were calculated using an extinction coefficient of $13.6 \times 10^{3} \mathrm{M}^{-1}$ of TNB at $412 \mathrm{~nm}$. The specific thioredoxin reductase activity was determined using the following equation: Specific activity $(\mathrm{U} / \mathrm{mg})=\mathrm{U} /$ total protein.

\subsection{Cell proliferation assay}

$0.5 \times 10^{6}$ cells were treated with the appropriate drugs for indicated period of time in 24-wells plate. Relative cell proliferation was assayed using the CellTiter-Blue Cell Viability Assay (Promega), as per the manufacturer's instructions.

\subsection{Western blot analysis}

Whole cell extracts were prepared using $0.5 \%(\mathrm{v} / \mathrm{v})$ Nonidet P-40 cell lysis buffer. Nuclear and cytosolic fractions were prepared using Nuclear Protein Extraction Kit (Cayman Chemicals) according to the manufacturer's guidelines. Western immunoblotting analysis was performed as described previously [40]. Blots were probed with various specific antibodies (HO-1, Nrf2, Lamin B1, HIF$1 \beta$, and $\beta$-tubulin) and ECL detection was done using GE ECL Western Blotting Substrate (GE Healthcare).

\subsection{Caspase-3 activity assay}

$0.5 \times 10^{6}$ cells were treated with the appropriate drugs for indicated period of time in 24-wells plate. Caspase-3 activity within the treated and untreated myeloma cell lines and PBMCs was determined as described previously following the cleavage of AcDEVD-AMC (Enzo Life Sciences, NY, USA), a caspase-3 substrate [26]. Briefly, treated or untreated cells $\left(0.5 \times 10^{6}\right.$ cells $)$ were pelleted, washed with PBS, re-suspended in 10-15 $\mu$ l of PBS, and transferred to black-walled 96-wells plate. $90 \mu \mathrm{l}$ of caspase assay buffer ( $5 \mathrm{mM}$ dithiothreitol, $100 \mathrm{mM}$ HEPES, 10\% (w/v) sucrose, $0.1 \% \mathrm{NP}-40$ at $\mathrm{pH} 7.25$ ) containing $50 \mu \mathrm{M}$ Ac-DEVD-AMC was added to the samples and the amount of AMC cleaved by caspase- 3 was measured at $37^{\circ} \mathrm{C}$ by measuring the fluorescence at excitation wavelength of $370 \mathrm{~nm}$ and emission of $445 \mathrm{~nm}$ using SpectraMax plate reader. 


\subsection{Measurement of intracellular ROS generation}

A dicholorofluorescein (DCF) assay was used to determine cellular ROS generation in myeloma cells and control PBMCs as described previously [26]. Briefly, $1 \times 10^{6}$ of treated or untreated

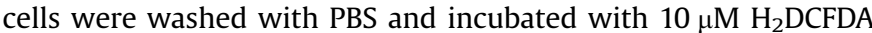
(Molecular probes, CA, USA), a redox sensitive cell permeable dye, for $15 \mathrm{~min}$. Cells were then transferred to black-walled clear-bottom 96-wells plate in triplicate and assessed for $\mathrm{H}_{2}$ DCFDA oxidation using a SpectraMax fluorescence plate reader (Molecular

A
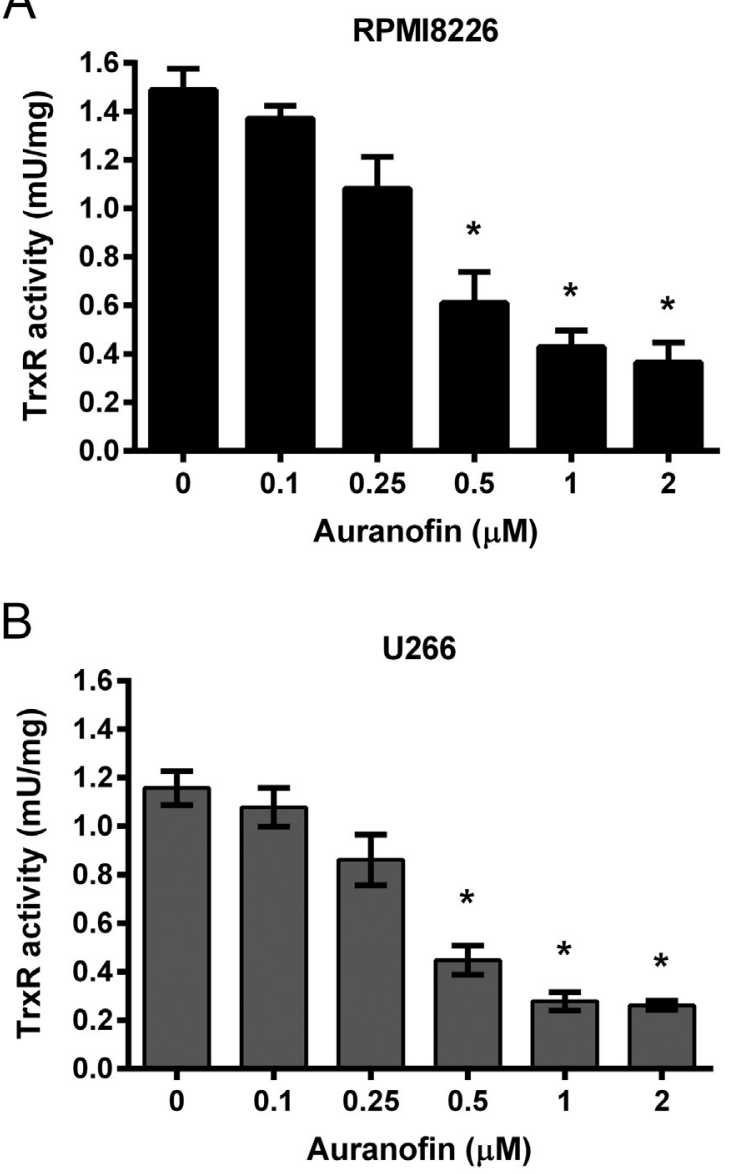

C

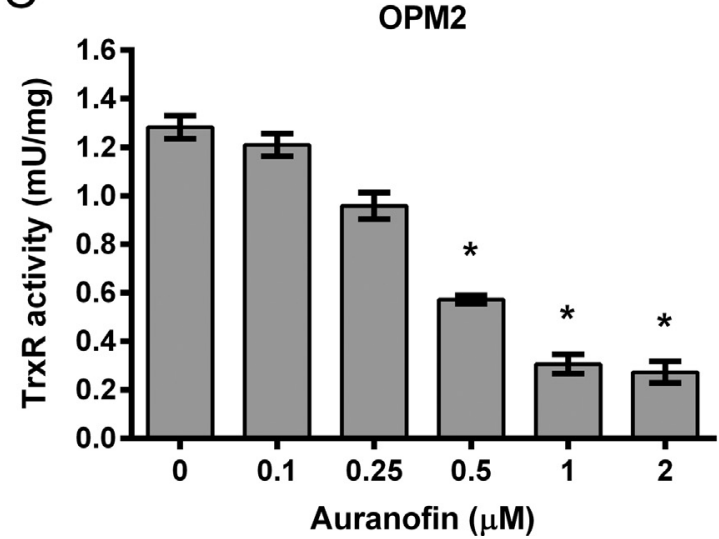

Devices). Data were analyzed using SoftMax Pro software (Biostrategy). The fluorescence intensity measuring the oxidation of $\mathrm{H}_{2}$ DCFDA by ROS represents the amount of intracellular ROS generation.

\subsection{Transient transfections}

Cells $\left(2 \times 10^{6}\right.$ per well) were transfected using Amaxa Nucleofector (T-001 program) using 2 ug of empty vector, pcDNA 3.1, and dominant negative-Nrf2 plasmids. Transfected cells were

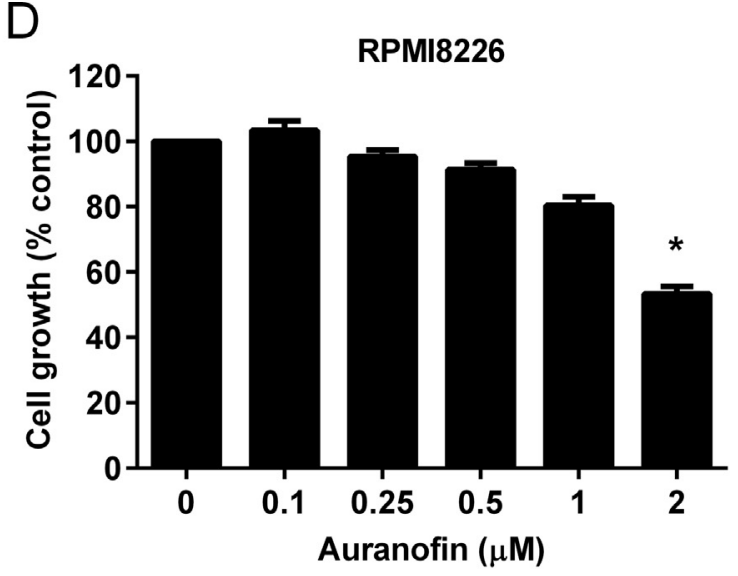

E
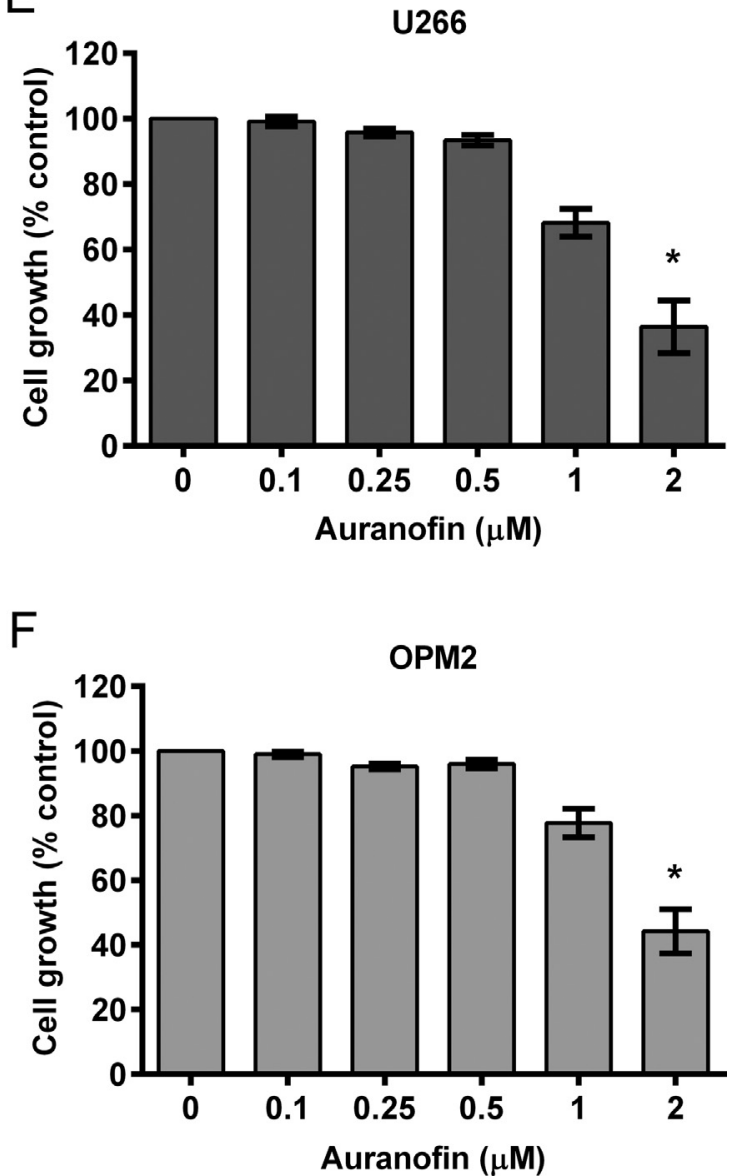

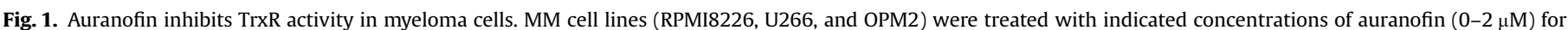

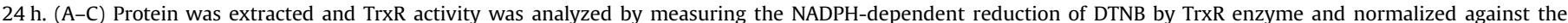

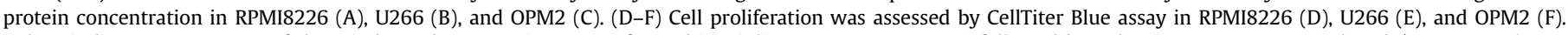

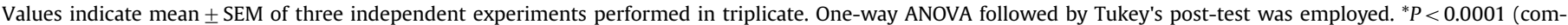
pared to the $0 \mu \mathrm{M}$ auranofin treatment). 
incubated for $24 \mathrm{~h}$ before the indicated treatments.

\subsection{RNA extraction and quantitative real time-PCR}

Total RNA was extracted from parent U266 and bortezomib-resistant (U266-BR) cells $\left(1 \times 10^{6}\right.$ cells) using TRIsure ${ }^{\mathrm{TM}}$ Lysis solution (Bioline) according to the manufacturer's instructions. Total RNA was reverse transcribed using the SensiFAST ${ }^{\mathrm{TM}}$ cDNA synthesis kit (Bioline). Resultant cDNA was analyzed by real-time quantitative PCR (RT-qPCR) using SensiFAST ${ }^{\mathrm{TM}}$ SYBR $^{\circledR}$ No-Rox Kit (Bioline) and RTqPCR primers for L32 [forward 5'-CAGGGTTCGTAGAAGATTCAAGGG$3^{\prime}$ and reverse 5'-CTTGGAGGAAAACATTGTGAGCGATC-3'] [41] and HO-1 [forward 5'-GCAGTCAGGCAGAGGGTGATAGAA-3' and reverse 5'-GGGCTCTGGTCCTTGGTGTCAT-3'] (Integrated DNA Technologies, IA, ISA), on the QuantStudio ${ }^{\circledR} 6$ Flex Real-Time PCR System (Applied Biosystems) according to the manufacturer's guidelines. Reaction conditions were $95^{\circ} \mathrm{C}$ for $5 \mathrm{~s}, 60^{\circ} \mathrm{C}$ for $10 \mathrm{~s}$, and $72{ }^{\circ} \mathrm{C}$ for $20 \mathrm{~s}$. The comparative cycle threshold algorithm $(\Delta \Delta \mathrm{Ct})$ method was used to analyze gene expression. The mRNA was normalized against L32 expression [41].

\subsection{Statistical analysis}

Data were analyzed by using the software GraphPad Prism 6 (GraphPad Software). Values are presented as mean \pm SEM. Statistical significance was determined by the specified statistical test. $P<0.05$ was considered significant.

\section{Results}

\subsection{Auranofin inhibits TrxR activity in myeloma cells}

We have previously shown that TrxR1 is upregulated in myeloma cells and auranofin, a TrxR inhibitor, induces myeloma cell death [26]. Here, we aimed to correlate auranofin-induced inhibition of TrxR activity with myeloma cell death and to study the interactions of TrxR with other antioxidants. Results showed that auranofin significantly inhibited TrxR activity in all three myeloma cell lines (RPMI8226, U266, and OPM2) and the $\mathrm{IC}_{50}$ value was achieved at $0.48 \mu \mathrm{M}, 0.46 \mu \mathrm{M}$, and $0.457 \mu \mathrm{M}$ in RPMI8226, U266, and OPM2 cells, respectively (Fig. $1 \mathrm{~A}-\mathrm{C}$ ). Interestingly, these auranofin concentrations were not sufficient to reduce cell proliferation and higher auranofin concentrations were required to significantly reduce cell proliferation in all three myeloma cell lines (Fig. 1D-F). We previously showed that auranofin treatment did not exert any significant cytotoxic effect on control peripheral blood mononuclear cells (PBMCs) [26].

\subsection{TrxR inhibition induces HO-1 expression on myeloma cells}

Based on the observed discrepancy in Auranofin concentrations required for inhibition of TrxR and cell proliferation, we hypothesized that TrxR inhibition may activate another antioxidant molecule, which may serve as a secondary anti-apoptotic mechanism in myeloma cells. Firstly, by using a publicly available gene expression database (GSE6477), we showed that HO-1 expression is significantly lower in new and relapsed MM patients compared to healthy individuals (Fig. 2A). Studies have shown that TrxR inhibition induces hepatic HO-1 expression [31]. Therefore, we investigated the effect of TrxR inhibition on HO- 1 expression in myeloma cells and control PBMCs. Western blot results showed a marked induction of HO-1 expression when TrxR activity was inhibited by $50 \%$ in all three myeloma cell lines (Fig. 2B-D). However, auranofin treatment did not induce $\mathrm{HO}-1$ protein expression in control PBMCs (Fig. 2E). In addition, we also investigated
A

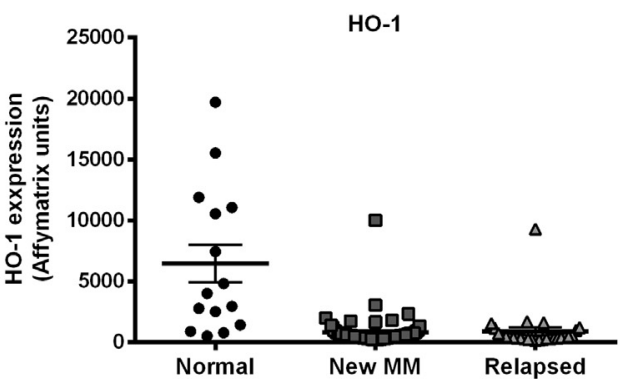

B RPMI8226
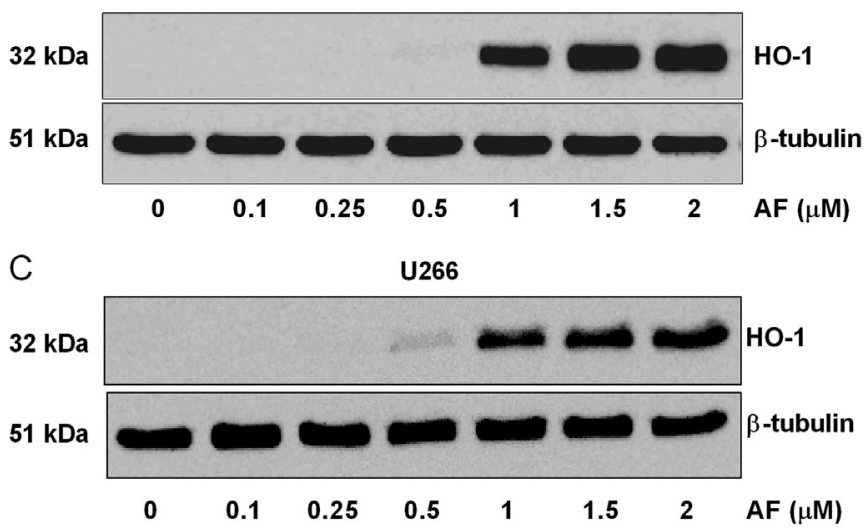

D OPM2

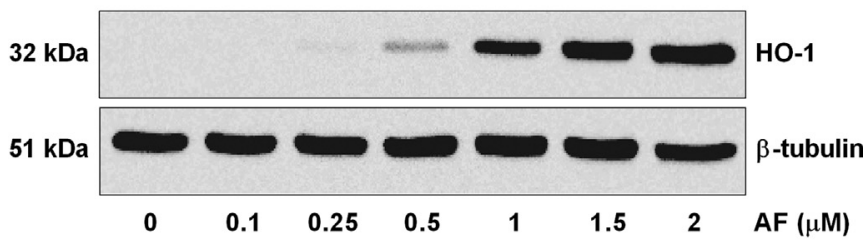

$E$

PBMC

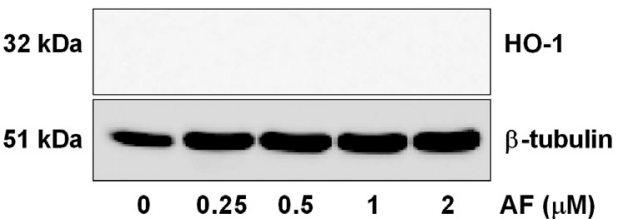

Fig. 2. TrxR inhibition induces HO-1 expression in myeloma cells. (A) Expression of HO-1 in myeloma patient cells (new MM and relapsed) and in normal cells were determined from the gene expression profile arrays deposited in the gene expression omnibus database (GSE6477). One-way ANOVA followed by Tukey's posttest were employed. $P<0.05$ (compared to the normal cells) (B-E) Myeloma cell lines RPMI8226 (B), U266 (C), OPM2 (D), and control PBMCs (E) were treated with indicated concentrations of auranofin (AF) $(0-2 \mu \mathrm{M})$ for $24 \mathrm{~h}$. Whole cell extracts were prepared, and HO-1 protein expression was analyzed by western blot analysis. $\beta$-tubulin was used as a loading. Western blots are representative of three independent experiments.

whether Trx1 inhibition induces HO-1 expression in myeloma cells. RPMI8226, U266, and OPM2 cells were treated with a Trx1 inhibitor, PX-12 $(0-20 \mu \mathrm{M})$, and $\mathrm{HO}-1$ protein expression was analyzed. Interestingly, targeting Trx1 did not induce HO-1 expression in myeloma cells at any concentration of PX-12 (data not shown).

\subsection{TrxR and HO-1 inhibition in conjunction induces apoptosis in} myeloma cells

We further analyzed whether increased HO-1 expression in response to TrxR inhibition can rescue myeloma cells from 
A

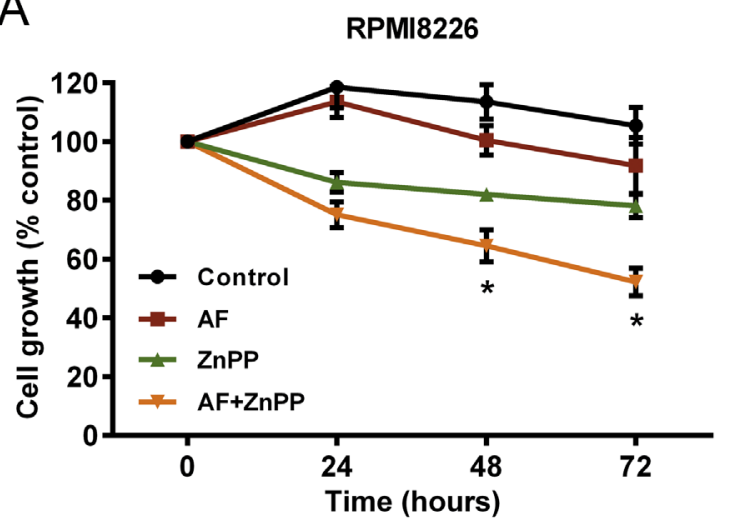

C

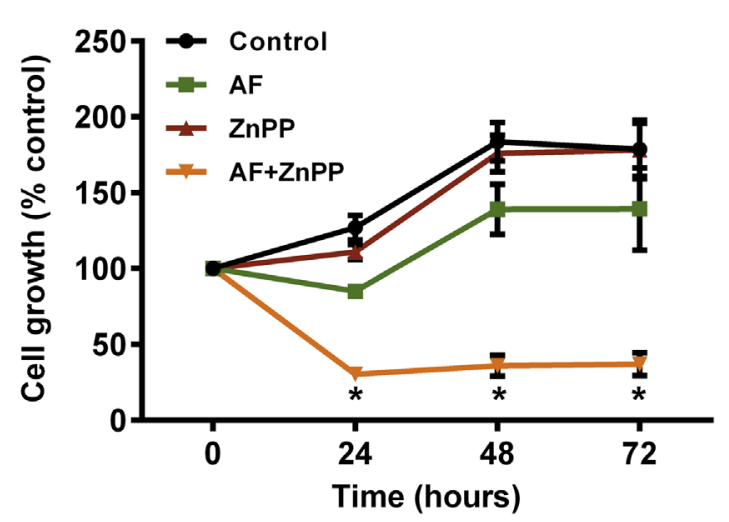

E

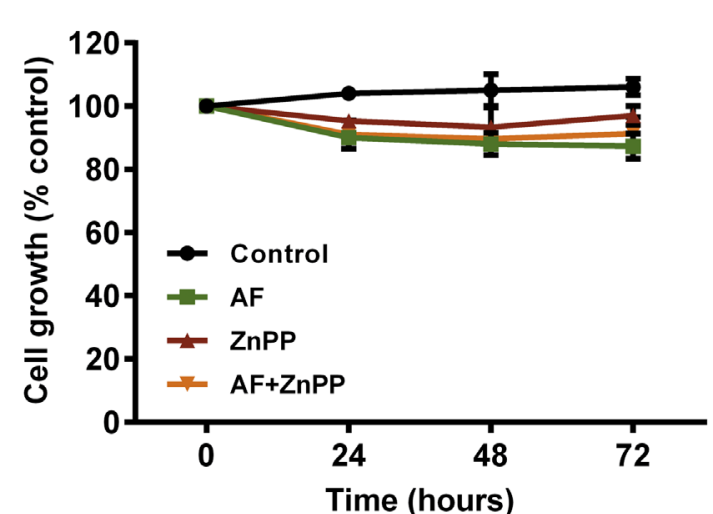

B

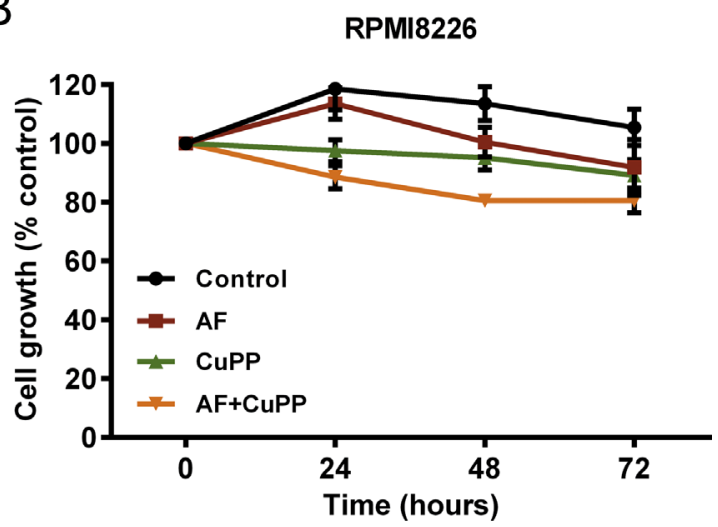

$\mathrm{D}$

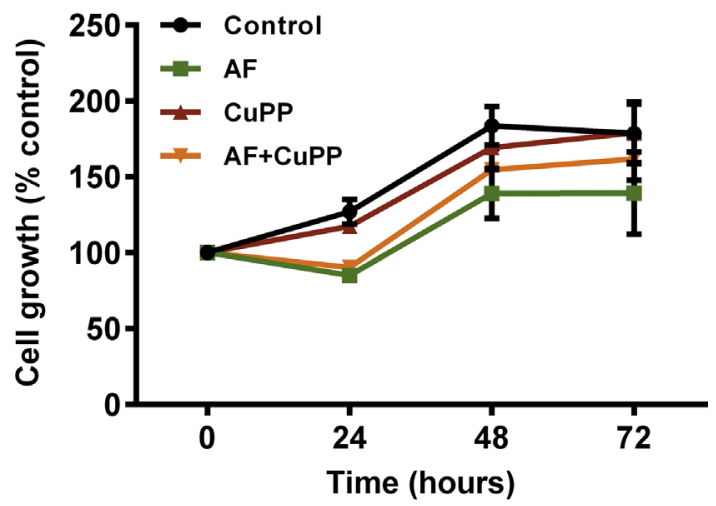

F

PBMC

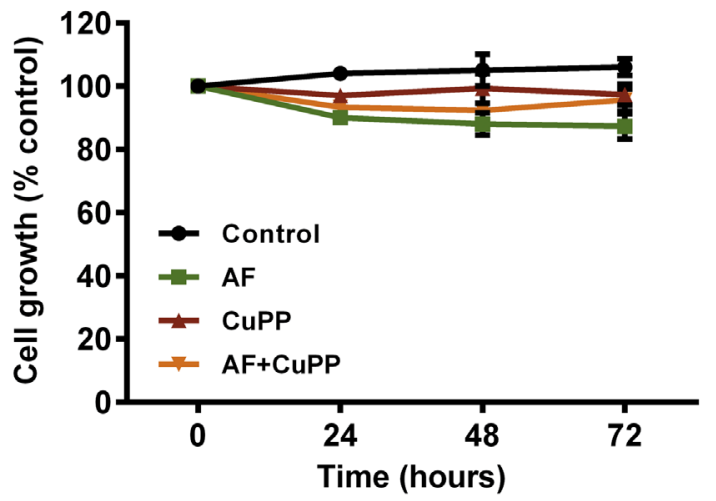

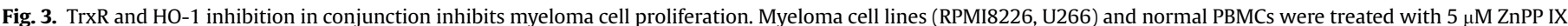

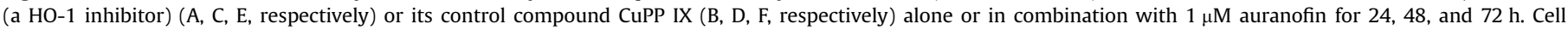

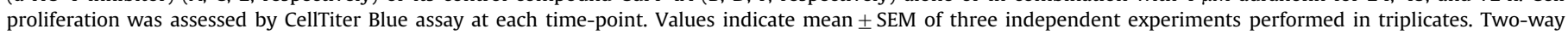
ANOVA followed by Sidak's post-test were employed. ${ }^{*} \mathrm{P}<0.05$ (compared to the cells treated with auranofin and ZnPP IX alone at each time-point).

undergoing cell death. To resolve whether inhibiting TrxR in combination with HO-1 can induce myeloma cell death, normal peripheral blood mononuclear cells (PBMCs), RPMI8226, and U266 cells were treated with $5 \mu \mathrm{M}$ Zinc Protoporphyrin IX (ZnPP IX) (an HO-1 inhibitor) or its control compound Copper Protoporphyrin IX (CuPP IX) and $1 \mu \mathrm{M}$ auranofin (a concentration that inhibits TrxR activity by more than $50 \%$ ) either alone or in combination for 24 , 48 , and $72 \mathrm{~h}$. To optimize the assays, myeloma cells were treated with increasing concentrations of ZnPP IX and CuPP IX $(0-10 \mu \mathrm{M})$ and a sub-lethal concentration of ZnPP IX, $5 \mu \mathrm{M}$, was selected for subsequent experiments (data not shown). In RPMI8226 cells, ZnPP IX, CuPP IX, and auranofin alone had little or no effect on the cell proliferation (Fig. $3 \mathrm{~A}$ and B). However, in combination with auranofin ZnPP IX (Fig. 3A), but not CuPP IX (Fig. 3B), significantly reduced RPMI8226 cell proliferation by approximately $35 \%$ and $50 \%$ after 48 and 72 h treatment, respectively. Similarly, in U266 cells, ZnPP IX, CuPP IX, and auranofin alone had no effect on cell proliferation (Fig. $3 \mathrm{C}$ and D). However, auranofin and ZnPP IX (Fig. 3C), but not CuPP IX (Fig. 3D), in combination significantly reduced U266 cell proliferation by approximately $70 \%$ after $24 \mathrm{~h}$ 
A

RPMI8226

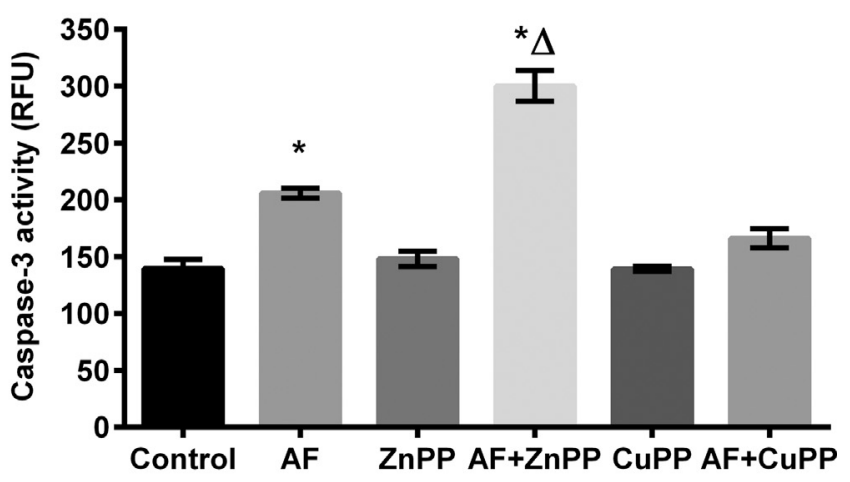

B

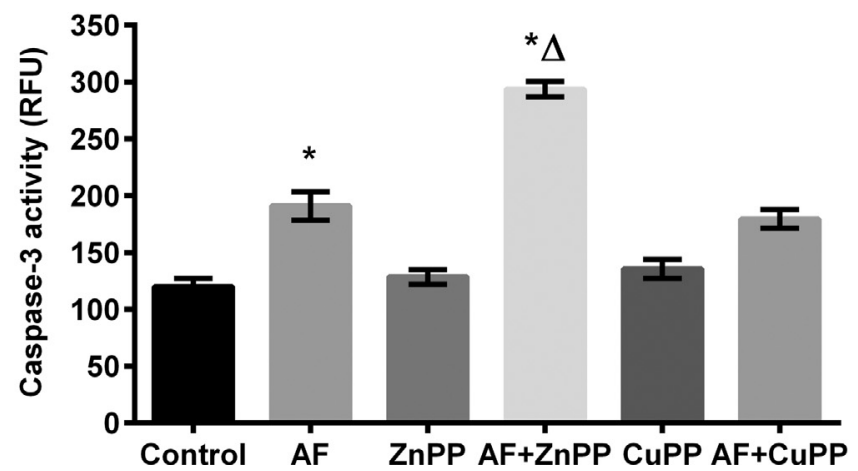

Fig. 4. Inhibiting TrxR in combination with $\mathrm{HO}-1$ induces myeloma cell apoptosis. (A, B) Myeloma cell lines RPMI8226 (A) and U266 (B) were treated with $5 \mu \mathrm{M} \mathrm{ZnPP}$ IX or its control compound CuPP IX alone or in combination with $1 \mu \mathrm{M}$ auranofin for $24 \mathrm{~h}$. Caspase-3 activity in treated and untreated cells was measured by monitoring the cleavage of Ac-DEVD-AMC. Values indicate mean \pm SEM of three independent experiments. One-way ANOVA followed by Tukey's post-test was employed. * (compared to the untreated control cells), $\Delta$ (compared to either AF alone or ZnPP IX alone), $P<0.05$.

treatment. Auranofin, ZnPP IX, and CuPP IX either alone or in combination exerted no significant cytotoxic effect on normal PBMCs (Fig. 3E and F).

We next examined the mode of myeloma cell death in response to TrxR and HO-1 inhibition. RPMI8226 and U266 cells were treated with $1 \mu \mathrm{M}$ auranofin and $5 \mu \mathrm{M}$ ZnPP IX either alone or in combination for $24 \mathrm{~h}$ and caspase- 3 activity was measured. Myeloma cells were also treated with $5 \mu \mathrm{M}$ CuPP IX and $1 \mu \mathrm{M}$ auranofin either alone or in combination as a control for ZnPP IX. Results showed that auranofin and ZnPP IX co-treatment significantly increased caspase- 3 activity by 2.2 -fold and 2.5 -fold in RPMI8226 (Fig. 4A) and U266 (Fig. 4B) cells, respectively, suggesting that myeloma cells are undergoing apoptosis when TrxR and HO-1 are co-inhibited. Treatment of myeloma cells with auranofin and CuPP IX together had no effect on caspase-3 activity (Fig. 4A and B).

\subsection{TrxR inhibition induces HO-1 expression in myeloma cells through Nrf2 activation}

Since HO- 1 is regulated by multiple transcription factors including Nrf2, NF- $\kappa \beta$, and AP-1, we investigated the underlying molecular mechanism by which TrxR may regulate HO- 1 in myeloma cells. RPMI8226 and U266 cells were treated with auranofin $(0-2 \mu \mathrm{M})$ for $24 \mathrm{~h}$, cytosolic and nuclear fractions were prepared, and Nrf2 and HO-1 protein expression was analyzed. Western blot results showed that auranofin-induced TrxR inhibition increased nuclear accumulation of Nrf2 in both RPMI8226 and U266 cells (Fig. 5A and B). As little as $0.25 \mu \mathrm{M}$ auranofin increased nuclear Nrf2 protein levels in both myeloma cell lines (Fig. 5A and B). Nrf2 protein levels were undetectable in the cytosolic fractions in both cell lines (data not shown). Western blot results also showed that TrxR inhibition increased HO-1 protein levels in both myeloma cell lines, which correlated with increased nuclear Nrf2 protein levels.

To confirm the involvement of the Nrf2 pathway in TrxRmediated HO-1 regulation in myeloma cells, we inhibited Nrf2 using dominant negative-Nrf2 (dn-Nrf2) [38]. U266 cells were transfected with dn-Nrf2 for $24 \mathrm{~h}$, subsequently treated with or without $1 \mu \mathrm{M}$ auranofin for $24 \mathrm{~h}$, and HO-1 protein expression was analyzed. Results showed a statistically significant decrease in HO1 protein levels in dn-Nrf2-transfected U266 cells after auranofin treatment compared to the control cells (Fig. 5C and D).

\subsection{ROS play an important role in TrxR-mediated HO-1 expression}

HO-1 has been shown to be involved in the regulation of redox equilibrium in human cells [42], and it is reported that intracellular ROS levels are increased when TrxR is inhibited [26]. We therefore examined the role of ROS in myeloma cells after TrxR and HO-1 inhibition. Control PBMCs and U266 cells were treated with auranofin $(1 \mu \mathrm{M})$ and ZnPP IX $(5 \mu \mathrm{M})$ alone or in combination for $24 \mathrm{~h}$ and ROS production and caspase-3 activity were measured. Results showed that intracellular ROS levels were increased when TrxR was inhibited (by 1.5-fold compared to untreated control) and were further increased when HO-1 was co-inhibited (by 2.2-fold compared to untreated control and 1.5-fold compared to TrxR inhibition alone) (Fig. 6A). No significant increase in intracellular ROS levels was observed when control PBMCs were treated with either auranofin or ZnPP alone or in combination (Fig. 6A). A ROS quencher, the antioxidant N-acetylcysteine (NAC), blocked the apoptotic response by inhibiting caspase-3 activity in U266 cells with both TrxR and HO-1-inhibited (Fig. 6B). This suggests that ROS are effectors of apoptosis in myeloma cells when TrxR and HO-1 are inhibited.

We then analyzed the role of ROS in TrxR-mediated HO- 1 expression in myeloma cells. RPMI8226 and U266 cells were treated with both auranofin $(1 \mu \mathrm{M})$ and NAC $(5 \mathrm{mM})$ either alone or in combination for $24 \mathrm{~h}$, and $\mathrm{HO}-1$ and $\mathrm{Nrf} 2$ protein expression were analyzed. Western blot results showed that auranofin-induced TrxR inhibition increased nuclear Nrf2 and cytosolic HO-1 protein levels in both MM cell lines (Fig. 6C). Addition of NAC markedly decreased both $\mathrm{Nrf} 2$ and $\mathrm{HO}-1$ protein levels in the nucleus and cytosol, respectively, in both myeloma cell lines (Fig. 6C). This suggests the involvement of ROS in TrxR-mediated HO-1 expression in myeloma cells.

\subsection{HO-1 inhibition overcomes bortezomib resistance in myeloma} cells

To investigate the role of $\mathrm{HO}-1$ in bortezomib resistant myeloma cells, we first analyzed HO-1 mRNA and protein levels in previously characterized bortezomib-resistant U266 (U266-BR) [26] and parent U266 cells. Significantly higher HO-1 mRNA levels were observed in U266-BR cells compared to the parent U266 cells (Fig. 7A). Western blot results showed that $10 \mathrm{nM}$ bortezomib treatment induced HO-1 protein expression in U266-BR cells, but lower concentrations of bortezomib did not induce HO-1 protein expression (Fig. 7B). To examine whether HO-1 inhibition overcomes bortezomib resistance in myeloma cells, U266-BR cells were treated with $10 \mu \mathrm{M} \mathrm{ZnPP}$ IX and $10 \mathrm{nM}$ bortezomib either alone or in combination for $48 \mathrm{~h}$ and cell proliferation was analyzed. While ZnPP IX and bortezomib alone had no effect on U266BR cell proliferation, ZnPP IX and bortezomib in combination 
A

RPMI8226

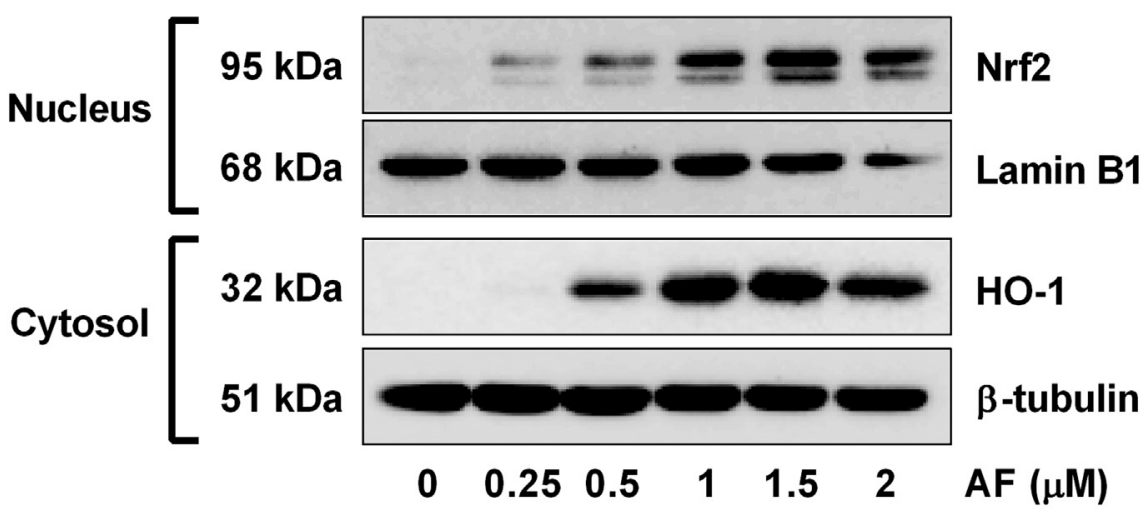

B

\section{U266}
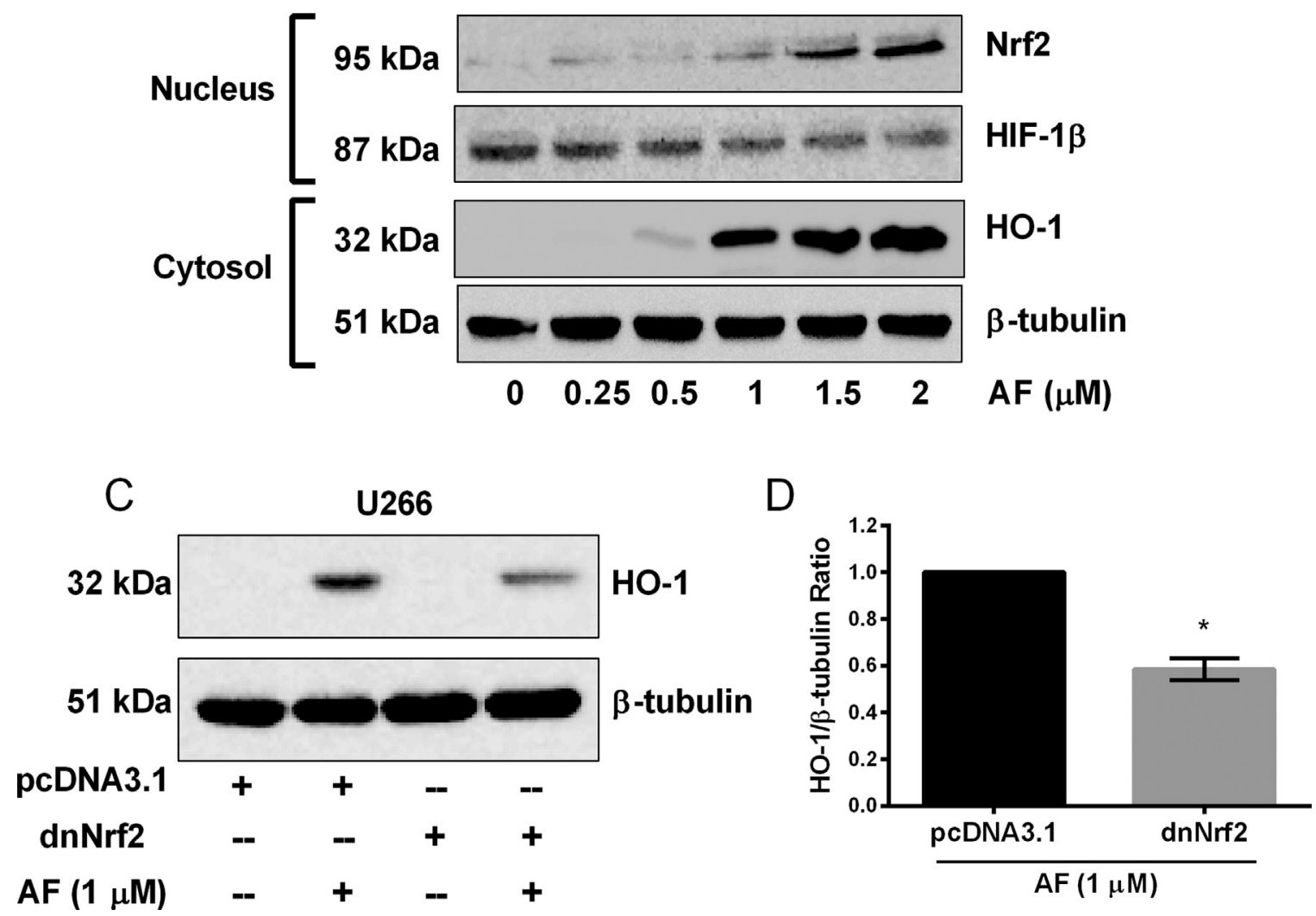

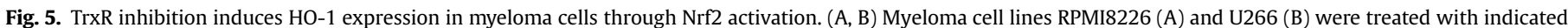

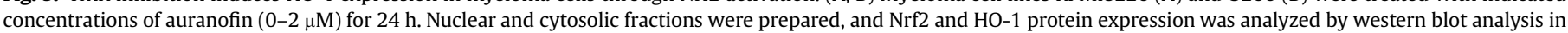

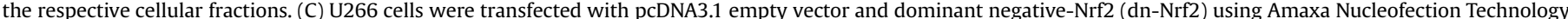

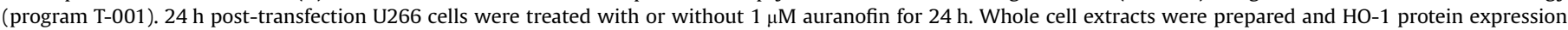

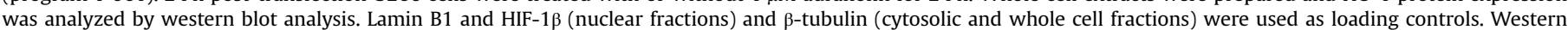

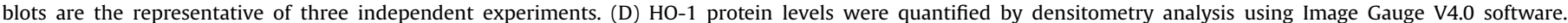
Quantification data are expressed as mean \pm SEM of three independent experiments. Unpaired student $t$ test was employed. ${ }^{*} P<0.05$.

significantly reduced U266-BR cell proliferation by approximately $50 \%$. Lower concentrations of ZnPP IX were also tested in combination with bortezomib (10 $\mathrm{nM})$, but no significant effect on cell proliferation was observed (data not shown).

\section{Discussion}

This study highlights the cross-talk between two antioxidants, TrxR and HO-1, in myeloma cells. We previously showed that
TrxR1 is upregulated in myeloma cells and its inhibition induced myeloma cell apoptosis [26]. This study showed that myeloma cell proliferation was not affected when TrxR activity was inhibited by more than $50 \%$ at lower auranofin concentrations (Fig. 1), suggesting the activation of another antioxidant system, which may act as a secondary anti-apoptotic mechanism. Previous studies suggested that glutathione and glutaredoxins systems rescue cells from apoptosis when TrxR is inhibited either by auranofin or aurothioglucose $[29,30]$. Our data showed that inhibition of TrxR activity by $50 \%$ induced $\mathrm{HO}-1$ protein expression in all three 
A

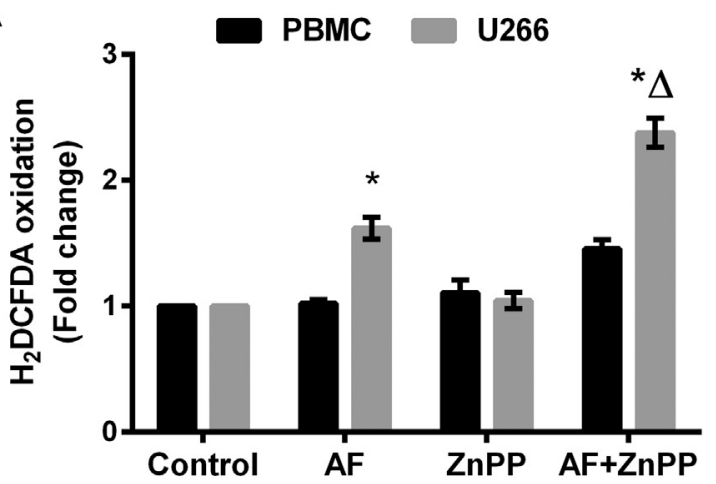

C

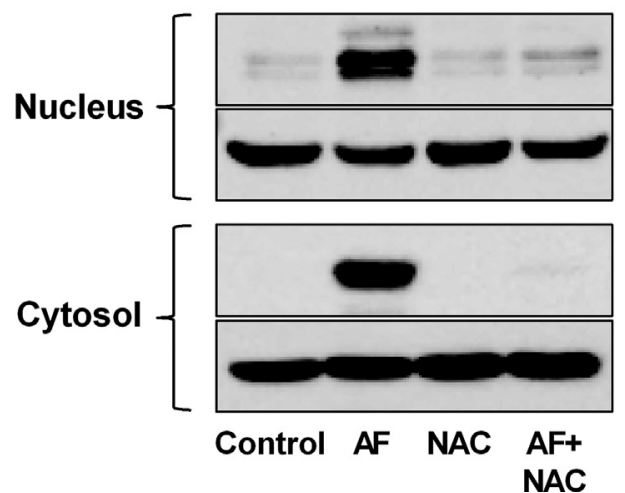

B

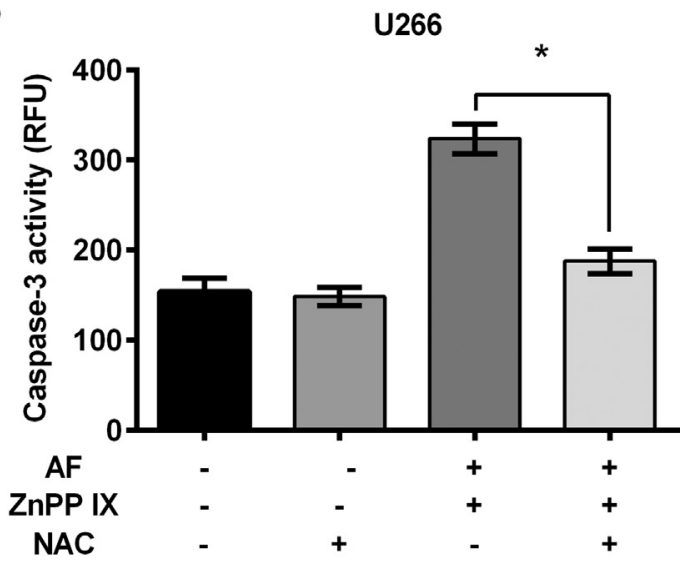

Nrf2 Lamin B1

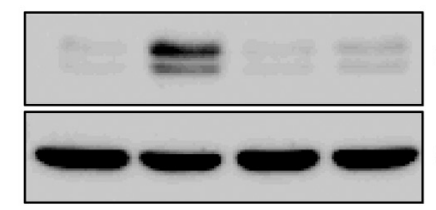

$95 \mathrm{kDa}$

$68 \mathrm{kDa}$

HO-1

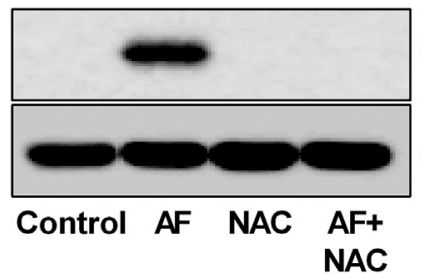

$32 \mathrm{kDa}$

$51 \mathrm{kDa}$

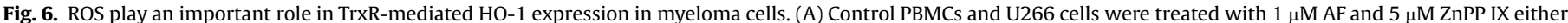

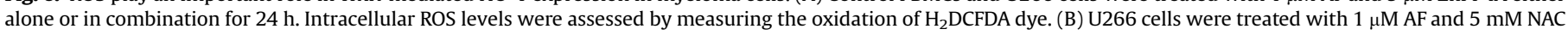

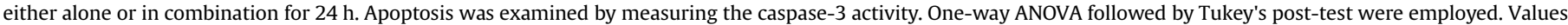

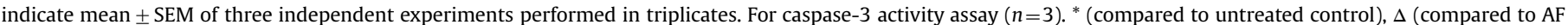
treatment alone), $P<0.05$.

myeloma cell lines (Fig. 2). Our data also showed that auranofin treatment did not induce HO-1 protein expression in control PBMCs, suggesting that the effect of TrxR inhibition on HO-1 expression is specific to myeloma cells. Thus, inhibition of TrxR activity by auranofin induces HO-1 expression in myeloma cells, which may serve as a secondary anti-apoptotic mechanism in TrxR-inhibited myeloma cells.

To our knowledge, this is the first study to report the therapeutic potential of inhibiting both TrxR and HO- 1 together in cancers. This study highlights the role of $\mathrm{HO}-1$ as a secondary antiapoptotic molecule in MM, which only becomes active when the primary defense mechanism such as TrxR, is inhibited. We showed that, like AML cells [20], MM patient cells have low HO-1 expression levels compared to healthy cells (Fig. 2). HO-1 expression has been shown to increase in AML cells upon treatment with chemotherapeutic agents such as cytarabine, daunorubicin, and bortezomib, and its inhibition sensitized AML cells to these drugs $[16,43]$. Moreover, arsenic trioxide treatment also increased HO-1 expression in different myeloma cell lines and its inhibition reduced myeloma cell proliferation [44]. In AML cells, HO-1 expression has been shown to increase in response to NF-к $\beta$ inhibition, and HO-1-inhibited AML cells became more susceptible to the NF-к $\beta$ inhibitor, BAY-11-7082 indicating that HO- 1 serves as a secondary anti-apoptotic mechanism in these cells [20]. Our results showed that HO-1 inhibition using ZnPP IX $(5 \mu \mathrm{M})$ in conjunction with auranofin $(1 \mu \mathrm{M})$ significantly reduced proliferation and induced apoptosis in myeloma cell lines (Figs. 3 and
4). However, ZnPP IX (5 $\mu \mathrm{M})$ and auranofin $(1 \mu \mathrm{M})$ in combination had no cytotoxic effect on normal PBMCs suggesting that this therapeutic combination can be a safe approach to treat MM patients. These findings indicate that $\mathrm{HO}-1$ serves as a secondary anti-apoptotic mechanism in myeloma cells and is upregulated to compensate for the loss of TrxR functions. Therefore, we suggest inhibiting HO-1 could potentially enhance the cytotoxic effect of TrxR inhibitors in myeloma cells with minimal adverse effect on normal cells. It has been shown that the presence of the HO-1 inhibitor, ZnPP IX, in vivo can enhance tumor responsiveness to anti-cancer agents [45]. Moreover, another study showed that TrxR1 knockdown upregulated the glutathione system in mouse embryonic fibroblasts and concomitant inhibition of TrxR1 and glutathione significantly reduced tumor growth in vivo [46]. Taken together, we suggest that inhibiting multiple antioxidant systems in combination may provide more effective therapeutic strategy to combat cancers including MM.

This study also highlighted a molecular mechanism by which TrxR inhibition induces HO-1 expression in myeloma cells. An oxidative stress sensitive transcription factor Nrf2 binds the antioxidant response element (ARE) located in the upstream promoter region of HO-1 [21]. In this study, we showed that auranofin treatment increased Nrf2 protein levels in the nucleus and HO-1 protein levels in the cytoplasm of myeloma cells (Fig. 5). Moreover, Nrf2 inhibition using a dn-Nrf2 expressing plasmid [38] significantly decreased HO-1 protein levels in response to TrxR inhibition (Fig. 5). Thus, our results indicated that TrxR inhibition 


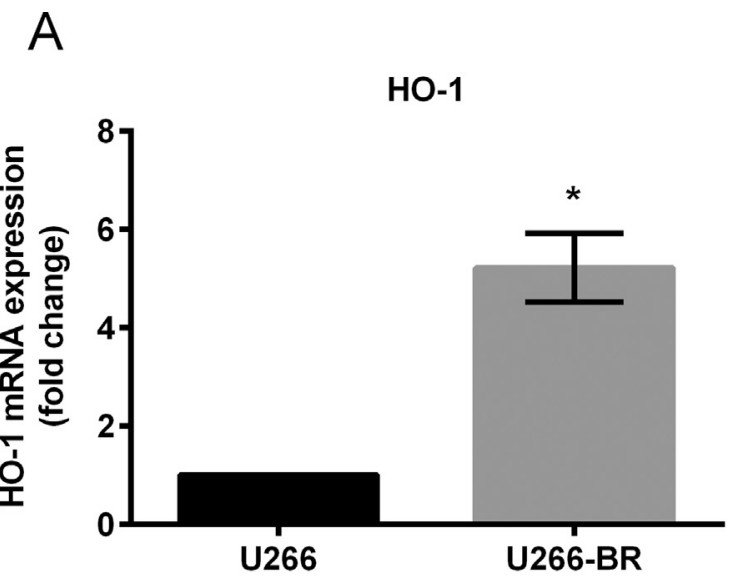

B

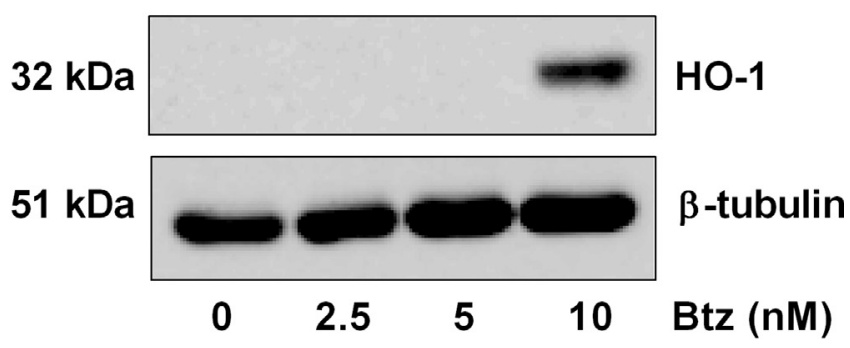

C

U266-BR

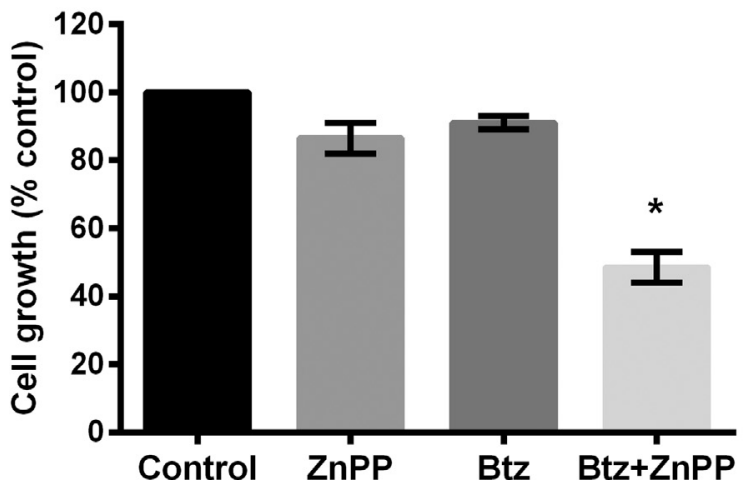

Fig. 7. HO-1 inhibition overcomes bortezomib resistance in myeloma cells. (A) HO1 mRNA levels were analyzed in parent U266 and bortezomib-resistant U266 (U266-BR) cells by RT-qPCR and normalized against L32 housekeeping gene. Values indicated mean \pm SEM $(n=3)$. Unpaired student $t$ test was employed. ${ }^{*} P<0.05$ (B) U266-BR cells were treated with indicated concentrations of bortezomib (Btz) $(0-10 \mathrm{nM})$ for $24 \mathrm{~h}$, whole cell extracts were prepared, and HO-1 protein expression was analyzed by Western blot analysis. $\beta$-tubulin was used as a loading control. Western blots are representative of three independent experiments. (C) U266-BR cells were treated with $10 \mu \mathrm{M}$ ZnPP IX and $10 \mathrm{nM}$ Btz either alone or in combination for $48 \mathrm{~h}$. Cell proliferation was assessed by CellTiter Blue assay. Values indicated mean \pm SEM of three independent experiments performed in triplicates. One-way ANOVA followed by Tukey's post-test were employed. ${ }^{*} P<0.05$ (compared to other treatment groups).

induces HO-1 expression through the Nrf2 transcriptional machinery in myeloma cells.

Our results showed that inhibiting TrxR and HO-1 in conjunction significantly increased intracellular ROS levels and caspase-3 activity (Fig. 6). Addition of NAC decreased caspase-3 activation in response to TrxR and HO-1 co-inhibition indicating that $\mathrm{HO}-1$ protects myeloma cells from apoptosis upon TrxR inhibition by removing ROS. Furthermore, we also showed that addition of NAC has markedly decreased nuclear Nrf2 and cytosolic HO-1 protein levels (Fig. 6). Thus, ROS plays a key role in TrxR-mediated HO-1 expression in myeloma cells. Previous studies have suggested that HO-1 protects AML cells from apoptosis in response to treatment with cytarabine, daunorubicin, and BAY-11-7082 by removing ROS generated by these drugs [16,20].

In recent years, $\mathrm{HO}-1$ has emerged as an effective drug target to overcome chemoresistance in many human cancer types. Upregulated enzymatic antioxidant defenses and stress-responsive proteins have been suggested as potential mechanisms responsible for drug resistance in cancer cells [47]. The gene expression profiling of docetaxel-resistant breast carcinoma patients revealed elevated levels of the antioxidant genes including Trx, glutathione, and peroxiredoxins [48]. Moreover, HO-1 expression was shown to be increased in recurrent or relapsed prostate cancer patients [49]. We and another group showed an increased HO1 mRNA levels in bortezomib-resistant myeloma cells [18], however, the functional role of HO-1 in overcoming bortezomib resistance in myeloma cells is unknown. Bortezomib-resistant myeloma cells have been shown to have increased Nrf2 mRNA levels compared to their parent counterpart [50]. Since Nrf2 regulates HO- 1 gene transcription by directly binding to the ARE site in the HO-1 promoter region [21], elevated Nrf2 levels may be responsible for the increased HO-1 transcript levels in bortezomibresistant myeloma cells. However, the exact molecular mechanism for the elevated HO-1 mRNA levels in bortezomib-resistant myeloma cells warrants further investigation.

This study, for the first time, highlights a novel strategy to overcome bortezomib resistance in MM by inhibiting HO- 1 . We showed that bortezomib treatment markedly increased HO-1 protein levels in U266-BR cells. Our data showed that HO-1 inhibition using its inhibitor, ZnPP IX, significantly restored the sensitivity to bortezomib in bortezomib-resistant myeloma cells (Fig. 7). Our data complements other studies where HO-1 inhibition using specific siRNA or its inhibitor, ZnPP IX, has been shown to increase the sensitivity of pancreatic cancer cells, cholangiocarcinoma cells, AML, and CML to chemo- and radiotherapy $[11,16,17,51]$. Thus, inhibition of HO-1 in combination with other conventional therapies may offer a novel approach to treat bortezomib-resistant relapsed/refractory MM patients.

In conclusion, we report that TrxR inhibition induces HO-1 expression and that inhibiting TrxR and HO-1 together induces myeloma cell apoptosis. Therefore HO-1 serves as a secondary anti-apoptotic mechanism in myeloma cells. Our findings suggest that HO-1 has a significant role in MM; however, this role of HO-1 is only revealed when TrxR activity is inhibited. Our findings further point towards the need of targeting multiple antioxidant systems to combat MM more effectively.

\section{Acknowledgments}

We thank A/Prof. Stephen Wood (Eskitis Institute, Brisbane, Australia) and his lab members for their help in setting up transfection experiments, Prof. George Mellick (Eskitis Institute, Brisbane, Australia) for collecting blood samples from healthy individuals, and Tony Blick (Queensland University of Technology, Australia) for his help in setting up the RT-qPCR. We also thank Dr. Xilin Chen (Atherogenics, USA) for providing us the dominant negative-Nrf2 plasmid.

This research was supported by a Griffith University Postgraduate Research Scholarship and a Griffith University International Post-graduate Scholarship (to P. R). We also thank Griffith University for providing financial support to carry out this 
research.

\section{References}

[1] M. Cavo, Proteasome inhibitor bortezomib for the treatment of multiple myeloma, Leukemia 20 (2006) 1341-1352, http://dx.doi.org/10.1038/sj. leu.2404278.

[2] A.K. Stewart, Carfilzomib for the treatment of patients with relapsed and/or refractory multiple myeloma, Future Oncol. 11 (2015) 2121-2136, http://dx. doi.org/10.2217/fon.15.123.

[3] A. Palumbo, T. Facon, P. Sonneveld, J. Blade, M. Offidani, F. Gay, P. Moreau, A. Waage, A. Spencer, H. Ludwig, M. Boccadoro, J.L. Harousseau, Thalidomide for treatment of multiple myeloma: 10 years later, Blood 111 (2008) 3968-3977, http://dx.doi.org/10.1182/blood-2007-10-117457.

[4] P.G. Richardson, E. Blood, C.S. Mitsiades, S. Jagannath, S.R. Zeldenrust, M. Alsina, R.L. Schlossman, S.V. Rajkumar, K.R. Desikan, T. Hideshima, N. C. Munshi, K. Kelly-Colson, D. Doss, M.L. McKenney, S. Gorelik, D. Warren, et al., A randomized phase 2 study of lenalidomide therapy for patients with relapsed or relapsed and refractory multiple myeloma, Blood 108 (2006) 3458-3464, http://dx.doi.org/10.1182/blood-2006-04-015909.

[5] M.D. Maines, Heme oxygenase: function, multiplicity, regulatory mechanisms, and clinical applications, FASEB J. 2 (1988) 2557-2568.

[6] R. Stocker, Y. Yamamoto, A.F. McDonagh, A.N. Glazer, B.N. Ames, Bilirubin is an antioxidant of possible physiological importance, Science 235 (1987) 1043-1046.

[7] D.E. Baranano, M. Rao, C.D. Ferris, S.H. Snyder, Biliverdin reductase: a major physiologic cytoprotectant, Proc. Natl. Acad. Sci. USA 99 (2002) 16093-16098, http://dx.doi.org/10.1073/pnas.252626999.

[8] L.E. Otterbein, M.P. Soares, K. Yamashita, F.H. Bach, Heme oxygenase-1: unleashing the protective properties of heme, Trends Immunol. 24 (2003) 449-455.

[9] T. Miyazaki, Y. Kirino, M. Takeno, S. Samukawa, M. Hama, M. Tanaka, S. Yamaji, A. Ueda, N. Tomita, H. Fujita, Y. Ishigatsubo, Expression of heme oxygenase-1 in human leukemic cells and its regulation by transcriptional repressor Bach1, Cancer Sci. 101 (2010) 1409-1416, http://dx.doi.org/10.1111/ j.1349-7006.2010.01550.x.

[10] A.I. Goodman, M. Choudhury, J.L. da Silva, M.L. Schwartzman, N.G. Abraham, Overexpression of the heme oxygenase gene in renal cell carcinoma, Proc. Soc. Exp. Biol. Med. 214 (1997) 54-61.

[11] P.O. Berberat, Z. Dambrauskas, A. Gulbinas, T. Giese, N. Giese, B. Kunzli, F. Autschbach, S. Meuer, M.W. Buchler, H. Friess, Inhibition of heme oxygenase-1 increases responsiveness of pancreatic cancer cells to anticancer treatment, Clin. Cancer Res. 11 (2005) 3790-3798, http://dx.doi.org/10.1158/ 1078-0432.CCR-04-2159.

[12] B.A. Schacter, P. Kurz, Alterations in microsomal drug metabolism and heme oxygenase activity in isolated hepatic parenchymal and sinusoidal cells in Murphy-Sturm lymphosarcoma-bearing rats, Clin. Investig. Med. 9 (1986) 150-155.

[13] A. Jozkowicz, H. Was, J. Dulak, Heme oxygenase-1 in tumors: is it a false friend? Antioxid. Redox Signal. 9 (2007) 2099-2117, http://dx.doi.org/10.1089/ ars.2007.1659.

[14] M. Mayerhofer, S. Florian, M.T. Krauth, K.J. Aichberger, M. Bilban, R. Marculescu, D. Printz, G. Fritsch, O. Wagner, E. Selzer, W.R. Sperr, P. Valent, C. Sillaber, Identification of heme oxygenase-1 as a novel BCR/ABL-dependent survival factor in chronic myeloid leukemia, Cancer Res. 64 (2004) 3148-3154.

[15] R.P. Wu, T. Hayashi, H.B. Cottam, G. Jin, S. Yao, C.C. Wu, M.D. Rosenbach, M. Corr, R.B. Schwab, D.A. Carson, Nrf2 responses and the therapeutic selectivity of electrophilic compounds in chronic lymphocytic leukemia, Proc. Natl. Acad. Sci. USA 107 (2010) 7479-7484, http://dx.doi.org/10.1073/ pnas.1002890107.

[16] S.A. Heasman, L. Zaitseva, K.M. Bowles, S.A. Rushworth, D.J. Macewan, Protection of acute myeloid leukaemia cells from apoptosis induced by front-line chemotherapeutics is mediated by haem oxygenase-1, Oncotarget 2 (2011) 658-668.

[17] M. Mayerhofer, K.V. Gleixner, J. Mayerhofer, G. Hoermann, E. Jaeger, K. J. Aichberger, R.G. Ott, K. Greish, H. Nakamura, S. Derdak, P. Samorapoompichit, W.F. Pickl, V. Sexl, H. Esterbauer, I. Schwarzinger, C. Sillaber, et al., Targeting of heat shock protein 32 (Hsp32)/heme oxygenase1 (HO-1) in leukemic cells in chronic myeloid leukemia: a novel approach to overcome resistance against imatinib, Blood 111 (2008) 2200-2210, http://dx. doi.org/10.1182/blood-2006-11-055723.

[18] L.N. Barrera, S.A. Rushworth, K.M. Bowles, D.J. MacEwan, Bortezomib induces heme oxygenase- 1 expression in multiple myeloma, Cell Cycle 11 (2012) 2248-2252, http://dx.doi.org/10.4161/cc.20343.

[19] Y. Lavrovsky, M.L. Schwartzman, R.D. Levere, A. Kappas, N.G. Abraham, Identification of binding sites for transcription factors NF-kappa B and AP-2 in the promoter region of the human heme oxygenase 1 gene, Proc. Natl. Acad. Sci. USA 91 (1994) 5987-5991.

[20] S.A. Rushworth, K.M. Bowles, P. Raninga, D.J. MacEwan, NF-kappaB-inhibited acute myeloid leukemia cells are rescued from apoptosis by heme oxygenase1 induction, Cancer Res. 70 (2010) 2973-2983, http://dx.doi.org/10.1158/ 0008-5472.CAN-09-3407.

[21] J. Alam, D. Stewart, C. Touchard, S. Boinapally, A.M. Choi, J.L. Cook, Nrf2, a
Cap'n'Collar transcription factor, regulates induction of the heme oxygenase-1 gene, J. Biol. Chem. 274 (1999) 26071-26078.

[22] S.L. Camhi, J. Alam, G.W. Wiegand, B.Y. Chin, A.M. Choi, Transcriptional activation of the HO-1 gene by lipopolysaccharide is mediated by $5^{\prime}$ distal enhancers: role of reactive oxygen intermediates and AP-1, Am. J. Respir. Cell Mol. Biol. 18 (1998) 226-234, http://dx.doi.org/10.1165/ajrcmb.18.2.2910.

[23] J. Sun, H. Hoshino, K. Takaku, O. Nakajima, A. Muto, H. Suzuki, S. Tashiro S. Takahashi, S. Shibahara, J. Alam, M.M. Taketo, M. Yamamoto, K. Igarashi, Hemoprotein Bach1 regulates enhancer availability of heme oxygenase-1 gene, EMBO J. 21 (2002) 5216-5224.

[24] A. Holmgren, Thioredoxin, Annu. Rev. Biochem. 54 (1985) 237-271, http://dx doi.org/10.1146/annurev.bi.54.070185.001321.

[25] D.T. Lincoln, E.M. Ali Emadi, K.F. Tonissen, F.M. Clarke, The thioredoxinthioredoxin reductase system: over-expression in human cancer, Anticancer Res. 23 (2003) 2425-2433.

[26] P.V. Raninga, G. Di Trapani, S. Vuckovic, M. Bhatia, K.F. Tonissen, Inhibition of thioredoxin 1 leads to apoptosis in drug-resistant multiple myeloma, Oncotarget 6 (2015) 15410-15424.

[27] P.V. Raninga, G. Di Trapani, K.F. Tonissen, Cross talk between two antioxidant systems, thioredoxin and DJ-1: consequences for cancer, Oncoscience 1 (2014) 95-110.

[28] D.F. Mahmood, A. Abderrazak, K. El Hadri, T. Simmet, M. Rouis, The thioredoxin system as a therapeutic target in human health and disease, Antioxid. Redox Signal. 19 (2013) 1266-1303, http://dx.doi.org/10.1089/ars.2012.4757.

[29] H. Zhang, Y. Du, X. Zhang, J. Lu, A. Holmgren, Glutaredoxin 2 reduces both thioredoxin 2 and thioredoxin 1 and protects cells from apoptosis induced by auranofin and 4-hydroxynonenal, Antioxid. Redox Signal. 21 (2014) 669-681, http://dx.doi.org/10.1089/ars.2013.5499.

[30] Y. Du, H. Zhang, J. Lu, A. Holmgren, Glutathione and glutaredoxin act as a backup of human thioredoxin reductase 1 to reduce thioredoxin 1 preventing cell death by aurothioglucose, J. Biol. Chem. 287 (2012) 38210-38219, http: //dx.doi.org/10.1074/jbc.M112.392225.

[31] V. Mostert, K.E. Hill, R.F. Burk, Loss of activity of the selenoenzyme thioredoxin reductase causes induction of hepatic heme oxygenase-1, FEBS Lett. 541 (2003) 85-88

[32] W.L. Trigona, I.K. Mullarky, Y. Cao, L.M. Sordillo, Thioredoxin reductase regulates the induction of haem oxygenase- 1 expression in aortic endothelial cells, Biochem. J. 394 (2006) 207-216, http://dx.doi.org/10.1042/BJ20050712.

[33] P. Wiesel, L.C. Foster, A. Pellacani, M.D. Layne, C.M. Hsieh, G.S. Huggins, P. Strauss, S.F. Yet, M.A. Perrella, Thioredoxin facilitates the induction of heme oxygenase-1 in response to inflammatory mediators, J. Biol. Chem. 275 (2000) 24840-24846, http://dx.doi.org/10.1074/jbc.M000835200.

[34] W. Fiskus, N. Saba, M. Shen, M. Ghias, J. Liu, S.D. Gupta, L. Chauhan, R. Rao, S. Gunewardena, K. Schorno, C.P. Austin, K. Maddocks, J. Byrd, A. Melnick, P. Huang, A. Wiestner, et al., Auranofin induces lethal oxidative and endoplasmic reticulum stress and exerts potent preclinical activity against chronic lymphocytic leukemia, Cancer Res. 74 (2014) 2520-2532, http://dx. doi.org/10.1158/0008-5472.CAN-13-2033.

[35] Y. Matsuoka, G.E. Moore, Y. Yagi, D. Pressman, Production of free light chains of immunoglobulin by a hematopoietic cell line derived from a patient with multiple myeloma, Proc. Soc. Exp. Biol. Med. 125 (1967) 1246-1250.

[36] K. Nilsson, H. Bennich, S.G. Johansson, J. Ponten, Established immunoglobulin producing myeloma (IgE) and lymphoblastoid (IgG) cell lines from an IgE myeloma patient, Clin. Exp. Immunol. 7 (1970) 477-489.

[37] S. Katagiri, T. Yonezawa, J. Kuyama, Y. Kanayama, K. Nishida, T. Abe, T. Tamaki, M. Ohnishi, S. Tarui, Two distinct human myeloma cell lines originating from one patient with myeloma, Int. J. Cancer 36 (1985) 241-246.

[38] X.L. Chen, S.E. Varner, A.S. Rao, J.Y. Grey, S. Thomas, C.K. Cook, M. A. Wasserman, R.M. Medford, A.K. Jaiswal, C. Kunsch, Laminar flow induction of antioxidant response element-mediated genes in endothelial cells. A nove anti-inflammatory mechanism, J. Biol. Chem. 278 (2003) 703-711, http://dx. doi.org/10.1074/jbc.M203161200.

[39] A.D. Smith, O.A. Levander, High-throughput 96-well microplate assays for determining specific activities of glutathione peroxidase and thioredoxin reductase, Methods Enzymol. 347 (2002) 113-121.

[40] T.C. Karlenius, F. Shah, G. Di Trapani, F.M. Clarke, K.F. Tonissen, Cycling hypoxia up-regulates thioredoxin levels in human MDA-MB-231 breast cancer cells, Biochem. Biophys. Res. Commun. 419 (2012) 350-355, http://dx.doi.org/ 10.1016/j.bbrc.2012.02.027.

[41] M.A. Lafleur, A.F. Drew, E.L. de Sousa, T. Blick, M. Bills, E.C. Walker, E. D. Williams, M. Waltham, E.W. Thompson, Upregulation of matrix metalloproteinases (MMPs) in breast cancer xenografts: a major induction of stroma MMP-13, Int. J. Cancer 114 (2005) 544-554, http://dx.doi.org/10.1002/ ijc.20763.

[42] J. Fang, T. Akaike, H. Maeda, Antiapoptotic role of heme oxygenase (HO) and the potential of $\mathrm{HO}$ as a target in anticancer treatment, Apoptosis 9 (2004) 27-35, http://dx.doi.org/10.1023/B:APPT.0000012119.83734.4e.

[43] S.A. Rushworth, K.M. Bowles, D.J. MacEwan, High basal nuclear levels of Nrf2 in acute myeloid leukemia reduces sensitivity to proteasome inhibitors, Cancer Res. 71 (2011) 1999-2009, http://dx.doi.org/10.1158/0008-5472. CAN-10-3018.

[44] P. Zhou, N. Kalakonda, R.L. Comenzo, Changes in gene expression profiles of multiple myeloma cells induced by arsenic trioxide (ATO): possible mechanisms to explain ATO resistance in vivo, Br. J. Haematol. 128 (2005) 636-644 http://dx.doi.org/10.1111/j.1365-2141.2005.05369.x.

[45] J. Fang, T. Sawa, T. Akaike, K. Greish, H. Maeda, Enhancement of 
chemotherapeutic response of tumor cells by a heme oxygenase inhibitor, pegylated zinc protoporphyrin, Int. J. Cancer 109 (2004) 1-8, http://dx.doi.org/ 10.1002/ijc.11644.

[46] P.K. Mandal, M. Schneider, P. Kolle, P. Kuhlencordt, H. Forster, H. Beck, G. W. Bornkamm, M. Conrad, Loss of thioredoxin reductase 1 renders tumors highly susceptible to pharmacologic glutathione deprivation, Cancer Res. 70 (2010) 9505-9514, http://dx.doi.org/10.1158/0008-5472.CAN-10-1509.

[47] M. Landriscina, F. Maddalena, G. Laudiero, F. Esposito, Adaptation to oxidative stress, chemoresistance, and cell survival, Antioxid. Redox Signal. 11 (2009) 2701-2716, http://dx.doi.org/10.1089/ars.2009.2692.

[48] K. Iwao-Koizumi, R. Matoba, N. Ueno, S.J. Kim, A. Ando, Y. Miyoshi, E. Maeda, S. Noguchi, K. Kato, Prediction of docetaxel response in human breast cancer by gene expression profiling, J. Clin. Oncol. 23 (2005) 422-431, http://dx.doi. org/10.1200/JCO.2005.09.078.
[49] Y. Li, J. Su, X. DingZhang, J. Zhang, M. Yoshimoto, S. Liu, K. Bijian, A. Gupta, J. A. Squire, M.A. Alaoui Jamali, T.A. Bismar, PTEN deletion and heme oxygenase1 overexpression cooperate in prostate cancer progression and are associated with adverse clinical outcome, J. Pathol. 224 (2011) 90-100, http://dx.doi.org/ 10.1002/path.2855.

[50] B. Li, J. Fu, P. Chen, X. Ge, Y. Li, I. Kuiatse, H. Wang, H. Wang, X. Zhang, R Z. Orlowski, The nuclear factor (erythroid-derived 2)-like 2 and proteasome maturation protein axis mediate bortezomib resistance in multiple myeloma, J. Biol. Chem. 290 (2015) 29854-29868, http://dx.doi.org/10.1074/jbc. M115.664953.

[51] S. Kongpetch, V. Kukongviriyapan, A. Prawan, L. Senggunprai,

U. Kukongviriyapan, B. Buranrat, Crucial role of heme oxygenase- 1 on the sensitivity of cholangiocarcinoma cells to chemotherapeutic agents, PLoS One 7 (2012) e34994, http://dx.doi.org/10.1371/journal.pone.0034994. 